\title{
PODER Y BENEFICIO. URBANIZACION $Y$ CAMBIO EN LA HISTORIA
}

\author{
DAVID R. RINGROSE \\ Universidad de California, San Diego
}

\section{INTRODUCCION}

Hace algunos meses esta revista publicó una interesante discusión sobre historia urbana basada en mi reciente obra, Madrid y la economía española, 1560-1850. En su artículo, el profesor Santos Madrazo, al tiempo que formulaba una serie de preguntas acerca de mi utilización de las fuentes, aludia también a problemas más interesantes relativos al lugar de la historia urbana en la estructura y en el proceso de cambio histórico ${ }^{1}$. En concreto, Madrazo menciona tres cuestiones interrelacionadas: a) la utilidad de los supuestos «smitheanos»; b) la premisa de que las ciudades producen unos fenómenos sociales y culturales únicos o nuevos, y $c$ ) el problema de la dependencia de interpretaciones ecológicas. Estos tres temas son los más interesantes e importantes, ya que tratan del lugar de las fuerzas motrices en la historia y, por lo tanto, mi respuesta a la crítica de detalles efectuada por Madrazo la he dejado para el apéndice.

\section{a) El supuesto smitbeano}

El interés del profesor Madrazo por mi enfoque «smitheano» y por la utilización de los mercados y del comercio para explicar el cambio es, posiblemente, una reacción a la afirmación de Smith sobre «... una cierta propensión en la naturaleza humana..., la propensión a hacer trueques, a permutar y a cambiar una cosa por otra" ${ }^{2}$, esto es, que el hombre es fundamentalmente un hombre económico. Evidentemente, éste es un postulado de la Ilustración que cuenta con serias limitaciones, limitaciones ya aparentes para algunos analistas del siglo xviII. Desgraciadamente, mi interés por los modelos comerciales y de mercado fue interpretado por el profesor Madrazo

${ }^{1}$ Madrazo Madrazo (1986); Ringrose (1985).

2 Smith (1937), p. 13. 
como un supuesto según el cual los hombres son actores sólo en tanto que son hombres económicos, aunque espero que este artículo pueda corregir esa visión.

\section{b) La novedad de los fenómenos urbanos}

El profesor Madrazo se lamenta de que, junto con Braudel, Foucault, Choay y otros, acepto el supuesto de que hay algo único en la ciudad que le hace desempeñar un papel transformador en la historia. Madrazo menciona a Manuel Castells ( sin dar ninguna referencia concreta), en el sentido de que no hay historia del espacio que no sea parte integrante de la historia social general. Por consiguiente, debemos centrar nuestra atención en «las estructuras de poder", pues la ciudad no es más que un producto de tales estructuras, y abandonar la idea de que la ciudad genera cultura, ya que las ciudades hacen que sea más fácil aceptar nuevas maneras de llevar a cabo las $\operatorname{cosas}^{3}$. Castells presenta a la ciudad sólo como un foco de tensión y de organización social para la gran sociedad (feudal) que la rodea. Examina la literatura que propone claramente una «cultura urbana» y la encuentra inadecuada en muchos aspectos. Considera la ciudad como un espacio al que se le ha asignado la «... tarea estructural... de acuerdo con la conflictiva dinámica social de la historia». «El proceso conflictivo entre los actores históricos en una sociedad dada asigna como objetivo a las ciudades en general la función estructural.» En otro lugar, Castells ofrece un resumen simplista de la historia urbana europea tomado de V. Gordon Childe, Gideon Sjoberg, Henri Pirenne y Max Weber, haciendo un uso bastante libre de términos tales como burguesa, feudal y aristocrática para clasificar las primeras ciudades europeas. Básicamente, su posición es que la ciudad en una civilización rural no es fundamentalmente distintiva ni única, sino que es simplemente un elemento dentro de dicha civilización - la otra cara de la misma moneda-. En cierto modo Castells tiene razón, hasta el punto de expresar un truismo. Sin embargo, al tiempo que da a entender que estas ciudades no añaden nada nuevo a la civilización, parece también implicar que la ciudad fue (al menos en la sociedad capitalista) un requisito previo para una división del trabajo más productiva.

Estoy de acuerdo con la premisa de que las ciudades son una extensión de un contexto más amplio en tanto que surgen para desempeñar las funciones que la sociedad rural llega a necesitar. Pero, en contra de la impresión

${ }^{3}$ Mis comentarios sobre Castells están tomados de Castells (1976), pp. 13-22 y 95-101, y Castells (1983), pp. XVIII-XIX, 4-14 y 291-303. Parece que la paráfrasis más directa de Madrazo procede de Castells (1976), p. 14. 
ofrecida por Castells, el papel de una ciudad es más complejo que el de ser un centro residencial para la élite social y un lugar para sus mecanismos de control social. Esta complejidad añadida, que Madrazo considera insignificante, puede ser lo que debamos examinar con más atención. Algunas grandes ciudades premodernas prestaban servicios centrales para más de un conjunto de estructuras económicas y geopolíticas. Al servir a un conjunto de estructuras, estas ciudades transmitían inevitablemente estímulos externos a otros conjuntos de estructuras con los que se hallaban relacionadas. Aunque sólo fuera porque concentraban a las élites políticas y económicas en un mismo nivel, tales ciudades también generaban en la sociedad factores políticos, sociales y económicos que parecen nuevos, y que incluian nuevas identidades y aspiraciones colectivas. Por consiguiente, al tiempo que la. urbanización fue fundamental para la coordinación y el control de la vida económica rural, proporcionó asimismo un lugar para que se dieran cambios que nunca se hubieran producido en una sociedad rural. Las ciudades fueron esenciales para la movilización y la redistribución de la riqueza, aun cuando no nos gusten los resultados. Por lo tanto, si es importante que conozcamos los mecanismos de control social (¿feudal?) que las ciudades simplemente albergaban, es también crucial entender cómo las ciudades influyeron en el hombre económico y en el mercado. Después de todo, incluso desde una perspectiva marxiana, los factores que producen la lucha y el cambio son externos a la estructura de control social dominante.

\section{c) Determinismo ecológico}

En el mismo estilo, Madrazo afirma que en lugar de depender del «determinismo ecológico» basado en la viabilidad del transporte, en la disponibilidad de recursos y en el clima, debemos reconocer que la estructura social refleja el control de los medios de producción. De este modo, las ciudades sólo son un reflejo de la estructura social, y son simplemente espacios en los que se sitúa la organización social de control. No obstante, a la luz de investigaciones recientes acerca de la formación de clases y el cambio social, me gustaría saber un poco más sobre lo que quiere decir el profesor Madrazo cuando se refiere al control social de los medios de producción 4 .

4 Para una discusión convincente sobre los problemas del análisis de clases en la historiografía reciente, véase Reddy (1987), pp. 1-33. 


\section{CULTURA Y PROCESO DE CAMBIO}

Así, a Madrazo le gustaría que abandonase el hombre económico, la unicidad de la cultura urbana y las restricciones ecológicas. Aunque no estoy dispuesto a llegar a esos extremos, creo que estoy más de acuerdo con él de lo que parece suponer. Los temas que esperaba plantear suponen, de hecho, la interacción de factores de mercado y de fuera de él. Tanto la psicología como la antropología, la literatura y el arte demuestran que la humanidad y sus sistemas de valores son mucho más complejos que lo que suponía la psicología de Locke y Bentham en la Ilustración. No obstante, el lado económico del hombre sí existe; entra normalmente en las decisiones humanas $y$, por lo tanto, influye en la forma que toman la mayoría de las instituciones con las que vivimos. Al mismo tiempo, debo hacer hincapié en que los factores ecológicos imponen limitaciones externas al cambio.

\section{a) Mercado y clase}

Tampoco estoy dispuesto a renunciar al empleo de modelos explicativos que convierten la lucha de clases en relaciones de intercambio de naturaleza recíproca, orientadas hacia el mercado o contractuales. Los intercambios de recursos escasos se encuentran asociados a veces (aunque no siempre) con mercados que fijan los precios y asignan los recursos para la producción. Históricamente, en algunos contextos culturales se les ha atribuido a los mercados un papel dominante o autónomo en el proceso de asignación. En otros, han formado parte o se han visto limitados por diversas instituciones, siendo «el mercado» uno de los distintos instrumentos institucionales utilizados para llevar a cabo las actividades de una sociedad, cuando ésta no confía en que los mercados sin control consigan los objetivos socialmente deseados. La navaja de Occam sugiere que la explicación menos complicada es con frecuencia la más exacta. La sensibilidad del mercado, y un cálculo de la utilidad personal, que incorpora los incentivos de mercado, ofrecen a veces explicaciones (o explicaciones parciales) del cambio que son más directas que las proporcionadas por el supuesto apriorístico de la primacía del control social y de la lucha de clases. Lo que es muy importante recordar cuando los historiadores continúan descubriendo el carácter evasivo de las clases como actores históricos y encuentran terriblemente difícil de relacionar sus supuestos «mejores intereses» con el comportamiento real.

$\mathrm{Ni}$ el análisis de mercado ni el de clases son necesariamente inválidos, ni se excluyen mutuamente. No obstante, algunas veces sus aplicaciones reflejan las distintas razones que tienen los historiadores para escribir historia. 
Las discusiones sobre la lucha de clases y la explotación expresan con frecuencia una indignación legítima (aunque anacrónica) por la injusticia de la distribución de la riqueza y del status en la sociedad, tanto actualmente como en el pasado. Frecuentemente, tales discusiones suponen que la vida es un juego de suma cero y, en ese contexto, se centran en la lucha social sobre la distribución de la riqueza. Aunque no niego que exista esa tensión crónica sobre la distribución de la riqueza, encuentro más interesante examinar en su lugar el proceso de cambio en la producción, la estructura, las fuentes, la cantidad y los mecanismos para la distribución de los bienes en la sociedad. Evidentemente, la estructura de control social influye sobre la manera en la que funcionan los procesos guiados por el mercado. Generalmente, esto ha dado lugar a una aparente contradicción entre una mayor eficiencia (según los estándares de la economía liberal y la estabilidad de las instituciones sociales existentes. Esta puede ser la misma contradicción inherente a cualquier discusión sobre la lucha de clases, pero esta manera de expresarlo nos permite dejar de lado la espinosa cuestión de la formación de las clases.

\section{b) Un enfoque antropológico de la redistribución}

Más que establecer falsas dicotomías entre la lucha social y las fuerzas de mercado o entre la sociedad urbana y la rural, prefiero un enfoque más interactivo. Cualquier cultura cuenta con mecanismos para la transferencia o el intercambio de bienes y servicios. Los antropólogos económicos como Karl Polanyi señalaron hace mucho tiempo que esta función la desempeñaban cuatro mecanismos diferentes: la economía doméstica, la reciprocidad, la redistribución y el intercambio de mercado ${ }^{5}$. La economía doméstica se asocia fundamentalmente con campesinos autosuficientes y los intercambios recíprocos resultan familiares a muchos historiadores en conexión con los héroes homériocs y las relaciones entre tribus ${ }^{6}$.

La redistribución efectuada a través de la autoridad y la administración supone, generalmente, una sociedad con un liderazgo político especializado, una élite militar y un clero. Todos ellos son grupos identificables que consumen bienes físicos sin producirlos. Si incluimos entre los mecanismos de redistribución la renta obtenida a la fuerza por una élite terrateniente, los diezmos recaudados por la Iglesia y los impuestos cobrados por la Corona, y si admitimos el empleo de piezas monetarias en el proceso de redistribución, introducimos en el concepto de instituciones económicas de redistribución la mayor parte de los intercambios de bienes y servicios asociados a los

s Hannerz (1980), pp. 80-83.

- Véase el ejemplo clásico de Papúa-Nueva Guinea en Malinowski (1922). 
términos feudalismo y Estado. Evidentemente, estas medidas redistributivas fueron, con frecuencia, explotadoras. Los imperios y las monarquías más tradicionales se basaron en la expropiación de una gran proporción de esa parte de la producción rural que no era necesaria para la simple supervivencia de la población trabajadora, y estos ingresos se utilizaban para que la élite mantuviese el control de la legitimidad religiosa y el empleo de la fuerza. Por consiguiente, al tiempo que unas pocas personas disfrutaban de estilos de vida suntuosos, se encontraban rodeados por una miseria generalizada: un modelo que supone de forma clara opresión y conflicto.

Los mercados representan una manera distinta de redistribuir los bienes, pero, dado el eterno problema de distribuir los recursos escasos, los mercados fueron, obviamente, tan opresivos intrínsecamente como otras formas de intercambio. En el modelo utópico de mercado, las personas producen bienes que no pueden consumir, y los cambian por los excedentes de otros productores. La interacción de la oferta, la demanda, el coste de producción y la urgencia de la necesidad maximiza la utilidad global y determina la relación de intercambio entre los bienes, una relación que se puede definir con piezas monetarias. Los mercados han existido en forma limitada desde hace miles de años. Sin embargo, en el contexto de las otras tres formas de intercambio, rara vez han estado sin regular y, por lo general, han sido sólo una de las diversas instituciones que redistribuyen la riqueza reflejando, así, la distribución de poder ${ }^{7}$. Sin regulaciones o limitaciones, el mercado puede, naturalmente, dejar a la gente en una situación enormemente desfavorable; puede ser manipulado por los actores más fuertes del mismo y puede hacer que comunidades enteras dependan de técnicas y actividades productivas que se abandonan después.

\section{EL ANTIGUO REGIMEN}

El contexto cultural del Antiguo Régimen europeo era tal que la mano de obra, los recursos naturales y el capital necesarios para producir bienes formaban parte (aunque de manera imperfecta) de un complejo de supuestos e instituciones sociales que aceptaban, sin discusión, la legitimidad de los cuatro modos de intercambio. La autoridad política se encontraba legitimada por una ideología religiosa de servicio y administración. Era un mundo con una tecnología primitiva y mucha pobreza. Su producción total sólo podía mantener a unas pocas familias en un estilo de vida holgado y no agrario. La sociedad europea que reflejaba esta realidad aceptaba que la vida era

\footnotetext{
' Polanyi (1957), pp. 43-44.
} 
corta, suponía que el cambio no era probable ni deseable y proclamaba que la vida en este mundo era menos importante que la vida más allá de la muerte.

Consideremos o no la ideología del status prescrito como un instrumento de control social de la élite feudal, ésta favoreció, sin duda, el supuesto de que los intercambios económicos eran parte de un juego de suma cero. Esto hizo que el cambio fuera sospechoso, ya que nueva riqueza en un lugar suponía automáticamente nueva pobreza en otro. Sólo hay que leer la crítica del comercio internacional de Colbert para comprender este supuesto fundamental. $Y$, sin embargo, al mismo tiempo fue una sociedad abierta a un cambio significativo, tanto en la esfera económica como en la política.

En esta ideología, la tierra, el trabajo y el dinero no estaban expuestos de forma automática a las fuerzas del mercado, sino que se encontraban sujetos a las limitaciones de una economía moral relacionada con los valores y los objetivos sociales tradicionales de la Edad Media. La tierra era un recurso social, y los derechos de propiedad estaban menos vinculados a la tierra que a parte del flujo de bienes que los campesinos obtenian de la tierra, Como se consideraba que las técnicas y los productos no variaban, importaba poco que los derechos de propiedad atribuyeran a menudo varios títulos parciales a una misma parcela de tierra, o que las tierras de muchos titulares (propietarios) se agruparan en una única empresa colectiva. Del mismo modo, el trabajo rara vez se encontraba separado del proceso doméstico de elaborar productos. Se suponía que los salarios reflejaban una renta moralmente justa, las regulaciones oficiales o gremiales sobre la producción en mercados poco activos distribuían y mantenían las rentas artesanales, mientras que se consideraba que los cambios de precios repentinos eran injustos y debían ser controlados. El dinero era utilizado habitualmente como medio de cambio $y$, ya en el siglo xVI, los tipos de interés y de cambio indican la existencia de complejos mercados monetarios. Sin embargo, los conceptos de la odiosa usura y de la caridad como medio de salvación reflejaban la ideología medieval de «buen gobierno» que consideraba el dinero como una institución útil, no como el mediador autónomo de los intercambios no regulados, o como un bien con su propio precio de mercado ${ }^{8}$.

Merezca la pena o no hablar de la transición del feudalismo al capitalismo, o incluso de una revolución burguesa ${ }^{9}$, mucho antes de la Revolución

- Sobre el empleo del dinero por la monarquía, véase Fox (1971), pp. 51.52, y, también, Polanyi (1957), pp. 68-76. Los análisis de Polanyi sobre la ayuda a los pobres y el patrón oro, aunque anticuados en muchos aspectos, presentan la posición cambiante en la sociedad de los factores básicos de producción.

Clavero (1979). 
Industrial, la Europa de los siglos xvir y xviII estaba ampliando de forma continuada la gama de actividades económicas a las que los mercados servían de intermediarios. Además, esta intermediación comenzó a incluir cada vez más no sólo productos acabados, sino factores básicos de producción. Hacia mediados del siglo xviI, una inmensa variedad de productos semielaborados y elaborados se intercambiaban de forma tan amplia y regular que, sin importar en qué mercado de Europa se introducían, sus precios se fijaban en las lonjas de Amsterdam. Este sistema de mercado relativamente libre penetró paso a paso en la vida económica local, influyendo en el intercambio regional, en las instituciones de redistribución y en la economía doméstica de los campesinos. Naturalmente, la paradoja de este proceso se encuentra en que, al mismo tiempo que las autoridades lo utilizaban conscientemente como un instrumento de redistribución, minaba los sistemas de redistribución tradicionales.

A medida que los hombres de los siglos xvil y xvili comenzaron a utilizar los mercados para mejorar o sustituir el poder redistribuidor de otras instituciones sociales y políticas, consideraron cada vez más a los factores básicos de producción como bienes de mercado ${ }^{10}$. El dinero se convirtió en un bien cuyo precio venía reflejado en la libre fluctuación de los tipos de interés y de los tipos de cambio internacionales. Las limitaciones morales sobre la usura desaparecieron gradualmente, y los gobiernos se volvieron reacios a dar subsidios a los pobres o a subordinar los tipos de interés a las preocupaciones sociales. En el siglo XIX, los flujos monetarios internacionales se vincularon cada vez más al patrón oro (o a la libra esterlina) que ligaba la oferta monetaria ( $\mathrm{y}$, con ello, los tipos de interés y los precios) al comercio internacional, frecuentemente, con efectos devastadores para las economías débiles.

A los trabajadores de todo tipo se les despojó de su «derecho al trabajo» o «derecho al sustento». De un status reconocido dentro de una jerarquía de orden divino que estaba obligada (en teoría) a proporcionar sustento a todos, los trabajadores pasaron a ser redefinidos como agentes independientes en un mercado de servicios laborales. A los gremios, las hermandades y los sindicatos, una vez parte integrante de un orden y de una jerarquía estable, se les calificó como agentes irracionales de privilegio. De esta forma, mientras que el Antiguo Régimen intentó racionalizar los gremios mediante la reducción de su capacidad de limitar la admisión de trabajadores a oficios específicos, después de la Revolución Francesa muchos gobiernos ostensiblemente tradicionales prohibieron estas organizaciones por considerarlas sub-

10 Para un tratamiento sugerente del proceso en Inglaterra, véase Appleby (1978), especialmente los caps. 1 y 3 . 
versivas políticamente y perjudiciales para el «libre mercado» de los servicios laborales.

Las tierras se dividieron en parcelas poseídas por propietarios individuales que eran libres de hacer lo que quisieran con «su» tierra. Las entidades colectivas (como el Estado o la Iglesia) que no tenían por objetivo la maximización de beneficios a través del mercado se convirtieron en propietarios ineficaces. Conforme se despojó a los trabajadores de su derecho moral al sustento, se liberó a la tierra de su responsabilidad social colectiva como recurso básico para la sociedad.

Lo anteriormente dicho presenta, naturalmente, varias formas ideales y simplificadas de transición. Los documentos muestran períodos y lugares en los que la comercialización de la tierra y del trabajo ya se encontraba establecida antes de que finalizara el siglo xvIII, y situaciones en las que los supuestos tradicionales continuaron hasta mucho después. Pero si seguimos a Polanyi, la subordinación generalizada y deliberada al mercado de los factores de producción anteriormente protegidos y regulados prevaleció sobre todo entre 1770 y 1870 .

\section{CIUDADES E INTERCAMBIO}

¿Cómo se relacionan estas generalizaciones tan amplias con las cuestiones planteadas por los comentarios de Madrazo sobre las ciudades? En el mundo real, los cuatro tipos de intercambio económico clasificados por los antropólogos existen de forma simultánea y lo han hecho así durante siglos. En el transcurso de los últimos tres mil años, los mecanismos de redistribución y de mercado han llegado a ser predominantes.

Aunque hubo muchas contradicciones y conflictos entre los dos, con frecuencia, se reforzaron mutuamente. Este proceso se hace especialmente claro en Europa a partir del siglo xIr. En ocasiones, el Estado redistribuidor ha costeado abiertamente la expansión del mercado. Sólo hay que pensar en las Cruzadas, la ayuda de Isabel I a Colón, el crecimiento de la Armada británica y las Leyes de Navegación inglesas. El mundo comercial correspondió a lo anterior concediendo créditos al Estado redistribuidor, créditos garantizados por los impuestos y las rentas esperadas que se utilizaron para todo desde la elección de Carlos $\mathrm{V}$ como emperador, pasando por la construcción de Versalles como un entretenimiento para la aristocracia francesa, hasta el establecimiento de los Bancos de Inglaterra y de San Carlos.

La misma utilización continuada y simultánea de más de un modo de distribución también existía desde hacía mucho tiempo en el campo. Los 
campesinos europeos pocas veces vivían en hogares realmente autónomos desde un punto de vista económico. Puede que tuvieran estrategias económicas orientadas hacia el hogar, pero continuamente estaban ocupados en legados y en dotes de novias, lo que supone la entrega de regalos recíprocos. También participaban en la base de la sociedad «feudal» o señorial proporcionando mano de obra, rentas, diezmos e impuestos que se determinaban de un modo tradicional, fuera del mercado. De este modo, constituían una parte fundamental del intercambio económico de redistribución. Al mismo tiempo, y en esto coincido con el profesor Madrazo, dieron lugar a una actividad de mercado local y regional en el que los distritos vecinos intercambiaban bienes de forma consuetudinaria y que suponía un contacto periódico con las ferias de comercio regionales. Así pues, en el siglo xviI, los campesinos de Segovia o de Avila tenían contactos de mercado reales, aunque tenues, que iban desde Bilbao a Madrid y a La Coruña. Puede que estos contactos fueran marginales a esta estrategia económica orientada hacia el hogar o la subsistencia, pero, no obstante, existían ".

Llegados a este punto, podemos vincular la discusión a las dos tendencias europeas que necesitamos tener en cuenta. Evidentemente, una de esas tendencias es la importancia cada vez mayor de los mercados como instituciones distribuidoras. La otra, que hasta ahora se ha puesto menos de relieve, es la centralización de la autoridad política conseguida por las monarquías de Europa. Estas cuestiones están claramente expuestas en el reciente estudio de Jan de Vries sobre la urbanización europea ${ }^{12}$. De Vries demuestra que el crecimiento urbano del siglo XVI se concentró en ciudades de tamaño medio (20-50.000 habitantes), mientras que en el siglo xvir, la migración hacia la ciudad se concentró en las grandes capitales políticas (entre las que se encontraba Madrid). Tras 1750 , el crecimiento de las ciudades muy grandes se redujo, al tiempo que la migración hacia la ciudad se concentró de nuevo en centros más pequeños, incluyendo nuevas adiciones al sistema urbano. Aunque la explicación de De Vries acerca de estos cambios del modelo no es siempre satisfactoria, presenta hipótesis de gran utilidad.

La urbanización del siglo xvi se caracterizó por un crecimiento de la población total y por una intensificación general de la actividad de mercado. Los gobiernos reales eran relativamente pequeños y descentralizados, y ninguna ciudad ocupaba un lugar dominante en toda Europa. El crecimiento urbano aparece como una consecuencia y un estímulo para la expansión económica rural. Si bien ayudó a mantener la expansión, la urbanización no

"Una descripción excelente de este modelo se encuentra en un libro de primera categoria: García Sanz (1986), pp. 172.198 y 246-252.

${ }^{12}$ De Vries (1984). 
transformó las estructuras básicas. La población regional y la urbanización regional se encontraban fuertemente interrelacionadas.

El siglo XVII produjo una reducción del crecimiento demográfico y económico europeo, pero también un aumento significativo del poder redistribuidor del Estado. Por mucho que se desee clasificar al Estado con relación a las élites dominantes en la sociedad, éste alcanzó un nivel de eficacia del que había carecido Europa durante más de mil años. Un control central más efectivo de los recursos aumentó las prebendas y los salarios distribuidos en la Corte y atrajo a muchos aristócratas, que contaban con rentas procedentes de sus propiedades. Por consiguiente, las capitales crecieron con rapidez, mientras que las ciudades de tamaño pequeño o mediano se estancaron o decayeron ${ }^{13}$. Puesto que tenían una tasa de mortalidad alta y una tasa de natalidad baja, las grandes ciudades sólo conseguían aumentar la población a través de la inmigración. De este modo, su crecimiento puede haber contribuido al estancamiento demográfico regional al absorber parte de los excedentes demográficos rurales normales.

Hacia mediados del siglo XVIII se dio una reorientación de la migración hacia los centros urbanos de tamaño medio, lo que vino acompañado de un crecimiento general de la población, de una intensificación de los intercambios de mercado, de la manufactura rural y de la agricultura especializada. El proceso es similar al del siglo xvi, excepto en dos cosas: 1) el número total de personas que vivían en las ciudades era significativamente mayor, al menos en el Noroeste de Europa, y 2) la expansión de los intercambios de mercado derivada del crecimiento demográfico se encontraba ahora ligada a una red comercial de larga distancia más eficiente. Para De Vries, el crecimiento sostenido de la población en el Noroeste de Europa contribuyó y fue fomentado por la intensificación de los vínculos de mercado, por la correspondiente diversidad de ventajas comparativas $\mathrm{y}$ por un número creciente de oportunidades para la manufactura rural. En donde se explotaron estas oportunidades, las comunidades rurales pudieron mantener más hogares, la gente se casó más joven y la población continuó creciendo, lo que, a su vez, reforzó la expansión demográfica y económica.

Cuando se concibe de esta manera, la realidad del intercambio económico de mercado y de redistribución es extremadamente compleja. Así, en contra de la afirmación del profesor Madrazo, para entender una economía regional es necesario hacer algo más que hablar en términos de los mecanismos de explotación. No tenemos más remedio que examinar la «circulación de las

${ }^{13}$ El colapso de las principales ciudades de Castilla la Vieja y de Castilla la Nueva entre 1580 y 1640 es el ejemplo más notable en Europa de este proceso, y la distribución geográfica de los ejemplos más graves del declive urbano relaciona el proceso de una manera clara, entre otros factores, con el ascenso de Madrid. Véase García Sanz (1985), p. 14. 
mercancías» y la interrelación entre los mercados urbanos y la economía rural. Puede que sea cierto, como indica Madrazo, que esos intercambios no produjeran cambios en las relaciones sociales y que sólo fueran síntomas de otros cambios más profundos en el control social de los medios de producción. No obstante, me gustaría señalar que la lucha por el control de los medios de producción y la búsqueda de ventajas en los intercambios de mercado se encuentran fuertemente interrelacionadas. Cada una de ellas tiene aspectos importantes que no proceden de la otra, y la relación es interactiva más que unidireccional. Por otro lado, su estudio puede darnos una idea más clara de quién controla realmente los medios de producción y en qué condiciones ${ }^{14}$.

En caso de que esto sea cierto, es importante comprender que tanto los intercambios de mercado como las transferencias económicas redistributivas dependen de los lugares centrales — ciudades y pueblos- para su coordinación. Así, los mercados locales, las ferias regionales, los puertos de mar, las sedes episcopales, las capitales de provincia, las Audiencias y las Cortes Reales proporcionaron un contexto para la coerción, la adjudicación y la negociación de intercambios.

En contra de lo que opina el profesor Madrazo, existe una clara relación entre la naturaleza de la urbanización, el crecimiento general de la población y el aumento de la producción por persona tanto en la agricultura como en la manufactura. Como indica Madrazo, parte de la orientación hacia la subsistencia de los hogares campesinos supone inevitablemente intercambios basados en una ventaja comparativa a corto plazo. Concurrentemente, el señor, la Iglesia o la Corona que acumulan rentas no son funcionalmente ricos, a menos que exista una manera de comercializar dicha acumulación, convirtiéndola, así, en otra forma de riqueza. Evidentemente, esto es una función comercializadora que convierte a la ciudad en una extensión del sistema de control de la élite de una manera bastante directa.

La dinámica básica del cambio poblacional produce con frecuencia una mayor población y una agricultura más intensiva; un proceso complejo que puede dar lugar a una grave crisis rural, pero que también puede resultar irreversible ${ }^{15}$. La intensificación y la especialización del trabajo rural, la comercialización de las rentas acumuladas y la comercialización de los excedentes de los campesinos en un ámbito local son susceptibles de interacción

${ }^{14}$ Un artículo reciente de Bartolomé Yun muestra que para algunos aristócratas las rentas de la tierra suponían una parte reducida de su renta total. Enrique Llopis analiza los cambios en los modelos de control de la tierra, demostrando que los beneficiarios no fueron necesariamente los aristócratas ni la burguesía urbana. Véanse Yun Casalilla (1985), pp. 443-472, y Llopis Agelán (1986), pp. 11-38.

15 Boserup (1965). 
con los núcleos centrales de liquidación de los intercambios a larga distancia. Esto sostiene el aumento de la población y de la productividad rural de forma que modifica la estructura social rural. Así, sea cual fuere la explicación de los orígenes de los mercados urbanos, su existencia en la Europa de los siglos XVII y xVIII supuso un estímulo importante para que más de un componente de la sociedad rural aumentara su productividad. Dependiendo de las circunstancias, estos estímulos fueron aprovechados por los campesinos, por los propietarios o por ambos con resultados económicos y sociales diferentes. Además, estos cambios fomentaron, a la vez que repondieron a, cambios similares en las ciudades.

\section{LA CIUDAD COMO LUGAR DE INNOVACION}

La cuestión que se plantea aquí es si es cierto y en qué momento el mundo urbano contribuye con algo nuevo al proceso de cambio. Ya que los cambios estructurales fundamentales aparecen, en el siglo xviII, tanto en la agricultura como en otras facetas de la economía, ésta es una cuestión que tiene que plantearse, aunque no sea respondida.

En contestación al análisis de Jan de Vries sobre la urbanización europea, E. A. Wrigley ha revisado su estudio sobre el crecimiento urbano y el cambio rural en Inglaterra ${ }^{16}$. Al reexaminar la relación entre el crecimiento urbano y la productividad rural en Inglaterra, Wrigley ha ampliado su esquema del binomio Londres/Inglaterra, sobre el que escribió en la década de 1960 , para incluir, en lo que se refiere al lado urbano, a toda la red regional de lugares centrales. También hace una distinción entre un crecimiento urbano comparable al crecimiento general de la población sin cambios estructurales (como en la Europa del siglo XVI) y un crecimiento urbano que excede el ritmo general de crecimiento de la población. Wrigley indica que el primer modelo continuó caracterizando a la Europa continental del siglo xviri, ya que las instituciones y la tecnología tradicionales retuvieron su vitalidad. Por el contrario, la población urbana de Inglaterra no sólo creció, sino que lo hizo a un ritmo más rápido que la población total. Para Wrigley, esto es prima facie una evidencia del aumento de la productividad agrícola y del cambio estructural.

De este modo, mientras que De Vries supone la existencia de una relación entre la mejora de los mercados, la protoindustrialización, el crecimien-

16 La discusión original citada por Madrazo se encuentra en Wrigely (1967), pp. 44-70. Pese a las afirmaciones de Madrazo de que Wrigley abandonó el tema, posteriormente trata de él en el libro de ensayos de Wrigley y Adams (1978). El ensayo más reciente que se menciona aquí es Wrigley (1986), pp. 123-168. 
to demográfico y la urbanización, Wrigley lleva el asunto un poco más lejos. Esencialmente, hace la misma pregunta que el profesor Madrazo: una vez que identificamos el cambio estructural, ¿cómo lo explicamos? En efecto, ¿quiénes deciden emplear las posibilidades coercitivas del Estado, la autoridad señorial y los mercados para reestructurar la producción y la distribución de manera significativamente nueva, y por qué se deciden a hacerlo? La identificación del catalizador se presenta, a menudo, como el problema fundamental, aunque la analogía a una reacción química puede ser engañosa, ya que fomenta nuestra preferencia natural por las explicaciones simples.

Wrigley introduce aquí el concepto de «innovación», que define como un intento deliberado de reorganizar los factores de producción en respuesta a las condiciones de mercado que prometen un beneficio mayor. Dado que esto parece contestar a la cuestión de quién promovió el cambio más que a la de por qué se hizo, su respuesta puede ser tanto una descripción como una explicación. Además, Wrigley relaciona demasiado estrechamente la innovación con el concepto «smitheano» de la racionalidad económica. Su sugerencia tampoco nos libera del problema de distinguir el papel del actor individual en comparación con el contexto ecológico para la acción, ya que las innovaciones que menciona requieren la existencia previa de instituciones que parecen nuevas en sí mismas. Estas innovaciones no son sólo los mercados, sino las definiciones de derechos de propiedad y la consiguiente apropiación de ganancias sociales como beneficio privado ${ }^{17}$.

Dichas condiciones pueden introducirse fácilmente en una lista que contenga todos los factores preexistentes. Sin embargo, muchos de esos factores eran también únicos a comienzos de la Europa moderna, mientras que su desarrollo es anterior al momento del que habla Wrigley. Por consiguiente, debemos enfrentarnos también a la cuestión de cómo surgieron estos factores. El efecto es el de desplazar aún más el problema de la «innovación» al pasado y al Antiguo Régimen.

Se me ocurre que aunque la innovación y el deseo de innovar son los conceptos fundamentales, no son exclusivos de situaciones inducidas por el mercado. De hecho, se encuentran presentes en innumerables situaciones, y surgen como una respuesta a la diversidad de necesidades o aspiraciones. La Europa de los objetivos espirituales medievales, de la jerarquía social, de la economía redistributiva y del Estado absolutista experimentó un cambio notable e innovaciones geniales. El éxito de las órdenes religiosas al imponer la religión y la autoridad españolas en América y la osadía estratégica de la reivindicación portuguesa del control sobre el comercio de las especias del Océano Indico e Indonesia son sólo dos ejemplos. La reorganización del

${ }^{17}$ Este es un problema de gran interés para North (1981), pp. 164-167. 
ejército francés llevada a cabo por Louvois y la creación de una infraestructura burocrática para mantenerlo representa una centralización de la autoridad política tan nueva e importante como la Revolución Industrial. No menos notable fue la reforma del Imperio americano español después de 1763 . Tales innovaciones en el ejercicio del poder, desde Luis XIV hasta Stalin y Hitler, han tenido una importancia trascendental.

Las innovaciones que aumentaron el potencial del Estado no se suelen discutir en el mismo contexto que las que produjeron la Revolución Industrial. La razón es obvia: los objetivos admitidos eran la salvación de las almas o el poder político más que la productividad y el beneficio, según los define la economía moderna. Reflejan un sistema de valores que subordina la propensión smitheana a realizar trueques y permutas a otros supuestos ideológicos.

La innovación se produce cuando las personas, en su deseo de proteger o de adquirir una posición, poder, prestigio, honor, santidad, riqueza y seguridad (en diversas combinaciones), adoptan decisiones que no tienen en cuenta las limitaciones convencionales. Las innovaciones resultantes se pueden proclamar como tales, como en la Ilustración y en la Revolución Francesa. Con más frecuencia, reflejan una elección entre opciones contradictorias, que parecen justificadas por la tradición. Estas innovaciones pueden ser muy difíciles de detectar, ya que, a menudo, venían acompañadas de racionalizaciones que eran, realmente, un camuflaje tradicional. Como en la Inglaterra de Wrigley, el resultado acumulativo puede redefinir los derechos de propiedad de la tierra y del trabajo, o puede, como en gran parte de Europa, redefinir las relaciones de poder entre las élites regionales y la autoridad central.

Si es éste el caso, puede que sea necesario cambiar el punto de mira a otro que suponga que la innovación es parte de la condición humana que surge de la necesidad periódica de resolver las contradicciones existenciales, una realidad reconocida hace mucho tiempo por los dramaturgos, desde Esquilo a Shakespeare. Las personas modifican, de este modo, las estructuras, aun cuando persiguen objetivos tradicionales legítimos. Muchos experimentos del siglo xviII realizados por el absolutismo ilustrado reflejan este hecho con claridad.

Inevitablemente, los innovadores sólo pueden predecir algunas de las consecuencias de sus innovaciones. Como saben la mayoría de los historiadores, esto es un proceso acumulativo que incluye la constante redefinición del pasado para legitimizar el presente -otra práctica que hace difícil distinguir una actividad que es tradicional de una que es nueva- ${ }^{18}$. Lo que es

"Los antropólogos culturales han entendido mejor este problema, y hablan del con- 
especialmente cierto, si consideramos los problemas relativos a la innovación planteados por economistas tales como Ester Boserup, antropólogos como Mark Cohen e historiadores como Carlo Cipolla ${ }^{19}$.

La característica de sus trabajos es apartar la cuestión del «primer descubrimiento» y trasladar la discusión a la acción individual en momentos de notoria necesidad. Boserup y otros señalan que todas las sociedades han tenido a su disposición, mediante la experiencia o la imitación, una amplia selección de técnicas políticas y productivas que no aprovecharon o que pusieron en práctica de una forma que a los europeos modernos les parece ineficiente o contraproducente. Boserup señala que desde la Prehistoria hasta el siglo xviı los agricultores conocían y hacían caso omiso de muchas técnicas que suponían una mayor productividad por hectárea o por trabajador. La realidad de estos «métodos perfeccionados» es que exigen más horas de trabajo. El aumento de la productividad por trabajador oculta el hecho de la disminución de la productividad por hora/hombre de trabajo.

Las sociedades agrícolas sólo han adoptado técnicas más intensivas en trabajo cuando la aversión por el trabajo físico que no está dignificado culturalmente se ve compensada por una clara necesidad o por la coerción. El principal motor de Boserup es el aumento de población en relación con los recursos, lo que origina una sensación de privación, si bien su determinismo demográfico se ve suavizado culturalmente de dos maneras: en primer lugar, un sentimiento de necesidad de origen cultural puede obligar a intensificar el trabajo antes de que se alcance una crisis malthusiana - lo que le añade a la lógica demográfica una dimensión cultural-; en segundo lugar, una vez que se haya establecido como costumbre un nivel determinado de trabajo, se puede convertir en una norma cultural. En tal caso, el no cumplimiento de las normas de trabajo definidas culturalmente produce un sentimiento de culpa, impidiendo una vuelta a niveles de trabajo inferiores.

De este modo, la innovación se hace mucho más compleja de lo que Wrigley parece suponer. Sea el individuo un campesino, un comerciante o un funcionario real, la naturaleza del momento innovador viene a depender, en gran medida, de su contexto. Si eso es verdad, el papel de la urbanización como estímulo del cambio (político o económico) puede ser más importante de lo que Madrazo indica ${ }^{20}$. Al menos, Wrigley busca los orígenes de la innovación económica en uno de los fenómenos que considera únicos a

trol de la historia y de la manipulación de los símbolos como parte del proceso de legitimación de la élite. Un buen ejemplo actual se encuentra en McDonough (1986), pp. 3.38.

19 Boserup (1965); Cohen (1977); Cipolla (1965); Cipolla (1978).

${ }^{20} \mathrm{Si}$ las categorías de clases que Castells y Madrazo aplican al mundo preindustrial demuestran ser demasiado simplistas y abstractas, quizás el enfoque de la disciplina monetaria sugerido por William Reddy merezca ser tenido en cuenta. Véase la nota 4. 
Inglaterra: una tasa de crecimiento urbano sin precedentes. Este autor no desarrolla la discusión, pero, cualquiera que fuera lo que causó el rápido crecimiento urbano, proporcionó mercados en expansión para la economía rural, del mismo modo que las ciudades se convirtieron en lugares donde se tomaban las decisiones acerca de la producción. Dudo que la urbanización de los lugares donde se tomaban las decisiones se diera únicamente en Inglaterra. De cualquiera manera, el hecho de que la toma de decisiones se produjera en las ciudades es crucial. La lógica nos obliga a ver las ciudades como la fuente de la innovación, y ése fue el contexto en que las relaciones de mercado y el poder centralizado penetraron en el modo de vida mucho más que en el mundo rural.

\section{AUTORIDAD POLITICA Y DOMINIO DE LOS MERCADOS}

Ahora debemos retomar los comentarios anteriores sobre las variedades del intercambio económico y la relación del mercado con la sociedad. Como vimos, el siglo xvir produjo una tendencia acelerada a subordinar parte de la sociedad y de los valores del Antiguo Régimen al juego de las fuerzas del mercado. Aunque no se desafió abiertamente la ideología de una economía moral, disminuyeron muchas de las restricciones al mercado como institución. Este hecho no fue tanto un reto al antiguo supuesto de que los mercados no deben controlarse, como una disposición a utilizarlos con más frecuencia para objetivos aparentemente tradicionales. Para citar un caso español conocido, el abastecimiento de Madrid se controló y reguló continuamente; no obstante, en el siglo xvirI, se sacaron de la administración directa y de los contratos regulados un sistema de abastecimiento tras otro. Cada vez se admitieron más agentes libres en el mercado urbano del trigo, del vino, del jabón y del carbón de leña. La intervención continuó, pero cada vez fue más esporádica. Esto fue confirmado de forma explícita por los regímenes liberales posteriores a 1835 , si bien el proceso comenzó a mediados del siglo xviII.

Douglas North y los historiadores económicos norteamericanos han destacado un resultado obvio del uso creciente del mercado como institución de distribución. Dados unos determinados derechos de propiedad, cuanto más controlaran los mercados la distribución, mayor era la posibilidad de que un innovador económico pudiera conseguir parte de los beneficios que había creado. Esto es muy importante para los historiadores que siguen la lógica smitheana criticada por Madrazo. El supuesto de Adam Smith y sus seguidores de que el hombre es un hombre económico hace coherente este 
modelo y permite explicar el crecimiento y el cambio por la respuesta del hombre a los mercados.

Con todo, me pregunto sobre la ideología y los motivos de los funcionarios de las ciudades que desregularon los mercados en el siglo xviri. No tenían ninguna experiencia directa de las realidades de la producción para los mercados. Parece más exacto considerar que su aculturación como miembros de la élite social incluía el cambiar sus supuestos sobre el mundo. Este condicionamiento de los administradores ilustrados les predispuso a suponer que los hombres eran hombres económicos smitheanos, pero de una manera abstracta y teórica bastante apartada de la realidad. Esta evolución semiconsciente de la ideología personal hizo que el mercado resultara atractivo a funcionarios acostumbrados a trabajar con abstracciones. De aqui que hombres con un conocimiento muy incompleto de cómo influían realmente las fuerzas del mercado en la sociedad facilitaran la subordinación de las necesidades humanas y personales a las fuerzas del mercado.

Lo que es evidente es que, comenzando en el siglo xviI, la urbanización europeo tomó una nueva estructura y un nuevo ritmo de crecimiento. La aceleración fue más obvia en Inglaterra, pero en toda Europa la introducción a través de las ciudades de los mercados en el mundo rural, el supuesto abstracto de la lógica del mercado de las autoridades tradicionales, el poder centralizado de las monarquías urbanas y el fracaso de una crisis demográfica a finales del siglo xviII, indican que las ciudades tuvieron mucho que ver con los cambios fundamentales que afectaron a los mercados, al comercio y a la política antes de que comenzara la Revolución Industrial.

Este es el marco conceptual de referencia que he utilizado para enfocar el problema del cambio en la España Moderna. Hace mucho que demostré la existencia de dos modelos característicos de transporte/intercambio en Castilla ${ }^{21}$. Uno atañe al transporte de productos básicos y de importaciones extranjeras a Madrid; el otro era una red interregional de intercambio de productos que unía a distritos rurales determinados. Esto ponía de relieve, en concreto, la participación campesina en las transacciones de mercado a pequeña escala, aunque también confirmaba la importancia de las distintas dotaciones y restricciones ecológicas regionales. Al mismo tiempo, Madrid era el único mercado disponible grande y concentrado. No era una ciudad moderna en ningún sentido económico, pero modernizó cada vez más las técnicas para mantener una capital tradicional. Esa modernización refleja, sin duda, una presión ejercida por elementos pertenecientes a la sociedad rural, aunque también procede de los nuevos hábitos de pensar del gobierno. Mi procupación nunca fue la de caracterizar la economía urbana de una forma

\footnotetext{
${ }^{21}$ Ringrose (1972).
} 
nueva, ni demostrar las relaciones de poder dentro de la sociedad urbana, sino determinar las interacciones reales entre la ciudad y el campo de una forma que aclarara el proceso de cambio en España en décadas posteriores. No intento proponer ni un «determinismo ecológico» ni la «circulación de las mercancías» como los únicos motores de la evolución histórica, aunque es absurdo suponer que los cambios acaecidos en la sociedad y en la vida económica se puedan explicar con una visión de la lucha de clases que es tan abstracta como el supuesto smitheano del hombre económico. Así, aunque puede que al profesor Madrazo no le resulte sorprendente que Madrid funcionara como lo hacía, a veces es conveniente confrontar los supuestos apriorísticos con la investigación empírica.

\section{APENDICE}

El profesor Madrazo lamenta que no utilizase la documentación de las alcabalas para reconstruir los flujos de mercancías. También lo lamento yo, pero esto no significa que mis fuentes sean inadecuadas. No me importaría que mis resultados fueran echados abajo por una reconstrucción más cuidadosa basada en otras fuentes. Aunque Estados Unidos pueda ser un país muy rico (un estereotipo que no siempre se puede aplicar a los profesores de universidad), los estudiosos norteamericanos no tienen el placer de vivir permanentemente junto a los archivos necesarios $y$, por tanto, no disponen del tiempo necesario para examinar las fuentes que parecen redundantes.

Asimismo, expresa su preocupación sobre algunos de mis intentos de extrapolar los niveles de consumo urbano. Confieso que intenté sacar demasiado de mis fuentes, por lo que recibiría con agrado datos mejor fundados. En cuanto a la comparación del consumo de trigo en 1630 y en 1847 , dado que los dos años tuvieron muy malas cosechas, las cifras concretas que cito ( 517.000 y 490.00 fanegas) no parecen tan fuera de lugar si se examina la tabla D.10 del Apéndice, en donde también menciono cifras para $1846 \mathrm{y}$ 1848. En este contexto, mis estimaciones de la población no son tan discordantes como da a entender Madrazo. Igualmente, el profesor Madrazo se queja de que mis estimaciones del consumo de vino per capita son demasiado altas. Madrazo no indica que discuto ese tema en la página 149, documentando situaciones análogas. También se lamenta de que el consumo «normal» de carne proyectado para 1630 sea superior al que extrapolo de las fuentes. Técnicamente lleva razón, pero lo que yo intentaba era reflejar la media de un período más largo y no el valor específico de un año atípico. El texto que hay en la página 145 es bastante claro acerca de esto. 
El tercer punto del profesor Madrazo se refiere a hipótesis que él considera basadas en datos inadecuados. Esta supuesta inadecuación procede, en parte, de la utilización de las cifras de peso mayor y correduría que no tienen cita y, en parte, de la comparación de las fechas aisladas de 1789 y 1847 . En el último caso, mi dependencia de datos procedentes de un único año atípico es inadecuada. Sin embargo, discuto los problemas inherentes a dichas fuentes fiscales. Madrazo lleva razón al afirmar que mi especulación sobre los curtidos es errónea. Pero su crítica no pone en tela de juicio, sino que igno$\mathrm{ra}$, unos comentarios análogos que hago sobre la más importante industria textil. Además, Madrazo no indica una discusión semejante sobre la estructura cambiante del consumo (pp. 163 y 446-447) que se basa en datos procedentes de una docena de mercancías distintas tomadas de 41 de los 72 años que van de 1776 a 1847 , la mayoría de ellos del siglo xIx. Admito de buen grado que, en ocasiones, he intentado extraer más conclusiones que las posibles de una fuente, pero mis ilusiones acerca del siglo xIx no son tan extremas como sugiere el profesor Madrazo.

No obstante, no estoy dispuesto a replantear las hipótesis sobre lo que quieren decir las cifras de peso mayor y correduría. Me disculpo por no documentar la fuente. Al editar el libro en inglés se perdió la parte del Apéndice $\mathrm{E}$ que enumeraba los datos impositivos consultados en el Arcbivo de la Villa de Madrid. La mayor parte de las citas necesarias aparecen en un artículo anterior ${ }^{22}$.

Madrazo lamenta las extrapolaciones que efectúo para la población total de Madrid, afirmando que la cifra de 154.000 inmigrantes en 24 años (16061630 ) es improbable. Volveré a mis fechas básicas (1597-1630), lo que nos da 34 años para este flujo, y una media de 4.500 inmigrantes al año. Dada la actividad constructora en Madrid, la pérdida de 40.000 personas en Toledo y el rápido declive de docenas de centros más pequeños en Castilla la Nueva, merece la pena tener en cuenta mi hipótesis hasta que se publiquen mejores datos. No he visto e! reciente trabajo de María Carbajo Isla, pero una breve referencia a sus estimaciones de que el Madrid de 1600 ya contaba con 90.000 personas supone una valiosa revisión de mi estimación. Realmente es un cambio que hará menos problemáticas algunas de mis otras proyecciones para ese período ${ }^{23}$.

Madrazo lleva bastante razón cuando afirma que Madrid era una pequeña parte de la población total de España, pero lo mismo se puede decir de la población urbana total. Lo que quiero señalar es que en la población de la red urbana de Castilla, Madrid era desproporcionadamente grande. Ello ocu-

\footnotetext{
22 Ringrose (1973).

${ }^{23}$ García Sanz (1985), p. 14.
} 
rría porque la ciudad se abastecía de Castilla, aunque también desempeñaba funciones que no se hallaban relacionadas con la vida económica de esa región.

En otra sección, el señor Madrazo se queja (quizás con ironía) de que insisto demasiado en el dualismo entre la ciudad y su binterland, y destaca los modelos de demografía urbana (núcleo y entorno) que mis fuentes del siglo xviII sólo confirman de manera provisional. Mi intención fue proyectar al siglo xviII ciertos modelos que eran evidentes en el siglo XIX. Esos modelos se encontraban estrechamente relacionados con otras estructuras que habían persistido de forma clara desde el siglo xviI al xIx. Considero válida la inferencia hasta que no se demuestre lo contrario y creo que el modelo núcleo/entorno es adecuado para entender la dinámica de la migración a la ciudad.

Posteriormente, Madrazo enumera una serie de temas relativos a la sociedad urbana que él y sus colegas están estudiando, e infiere que también yo debía haberlo hecho. Esto es quejarse del libro que decidí no escribir. Mi libro no es realmente sobre Madrid, sino sobre la relación de Madrid con su binterland. Esto no es dualismo, sino un vínculo perenne; en esto estoy de acuerdo con Madrazo. Sin embargo, es la relación la que cambia, y esos cambios, condicionados en parte por la estructura económica de la propia ciudad, son los que he intentado destacar. En cuanto al comentario de que Madrid no influyó en el declive de algunas ciudades castellanas, y que los cambios en las relaciones comerciales no explican la dinámica socioeconómica, tengo dos respuestas. El profesor Madrazo simplemente no ha entendido el modelo de interdependencia dentro de la red urbana que he propuesto; en su lugar, ha buscado explicación donde yo únicamente he intentado demostrar que las interacciones cambian. Indudablemente, esos cambios necesitan más explicación.

(Traducido por Angelines Conde Gutiérrez del Alamo.) 


\section{BIBLIOGRAFIA}

APPLeBy, Joyce O. (1978): Economic Thought and Ideology in Seventeenth-Century England, Princeton, Princeton University Press.

Boserup, Ester (1965): Conditions of Agricultural Growth: The Economics of Agrarian Change Under Population Pressure, Chicago, Aldine Press.

Castells, Manuel (1976): Le cuestión urbana, Madrid, Siglo XXI.

- (1983): The City and the Grassroots: A Cross-Cultural Theory of Urban Social Mo. vements, Berkeley, University of California Press.

Cipolla, Carlo (1978): Clocks and Culture, 1300-1700, Nueva York, Norton.

- (1965): Guns and Sails in the Early Phase of European Expansion, 1400-1700, Londres, Collins.

Clavero, Bartolomé (1979): «Política de un problema: la Revolución Burguesa», en Bartolomé Clavero, Pedro Ruiz Torres y F. J. Hernández Montalbán, Estudios sobre la revolución burguesa en España, Madrid, Siglo XXI.

Co HeN, Mark Nathan (1977): The Food Crisis in Prebistory: Overpopulation and the Origins of Agriculture, New Haven, Yale University Press.

DE VRIES, Jan (1984): European Urbanization, 1500-1800, Londres, Methuen.

Fox, E. W. (1971): History in Geographical Perspective, Nueva York, Norton.

García Sanz, Angel (1985): “Auge y decadencia en España en los siglos xvi y xviI: Economía y sociedad en Castilla», Revista de Historia ECONÓmiCA, III.

- (1986): Desarrollo y crisis del Antiguo Régimen en Castilla la Vieja, Madrid, Akal.

Hannerz, Ulf (1980): Exploring the City: Inquiries Toward an Urban Antbropology, Nueva York, Columbia University Press.

LlopIS AGELÁN, Enrique (1986): «El agro castellano en el siglo xvir: ¿Depresión o "reajustes y adaptaciones"?», RevisTa DE Historia ECONÓmICA, IV, pp. 11-38.

Madrazo Madrazo, Santós (1986): «La lógica "smitheana" en la historia económica y social de Madrid. A propósito de una traducción reciente», REvisTa DE HISTORIA ECONÓMICA, IV, pp. 609-618.

Malinowski, Bronislaw (1922): Argonauts of the Western Pacific, Londres.

McDonougr, Gary Wray (1986): Good Families of Barcelona: A Social History of Power in the Industrial Era, Princeton, Princeton University Press.

NorT H, Douglass (1981): Structure and Change in Economic History, Nueva York, Norton.

Polany1, Karl (1957): The Great Transformation: Political and Economic Origins of Our Time, Boston, Beacon Press.

REDDY, William M. (1987): Money and Liberty in Modern Europe, Cambridge, Cambridge University Press.

RINGROSE, David R. (1985): Madrid y la economía española, 1560-1850, Madrid, Alianza.

- (1973): «Perspectives on the Economy of Eighteenth-Century Spain», en Historia Ibérica: Economía y sociedad en los siglos XVIII y XIX, Nueva York/Salamanca, Las Américas/Anaya.

- (1972): Los transportes y el estancamiento económico de España, 1750-1850, Madrid, Tecnos.

SMITH, Adam (1937): An Inquiry into the Nature and Cause of the Wealth of Nations, Nueva York, Random House.

WRIGLEY, E. A. (1967): «A Simple Model of London's Importance in Changing English Society and Economy», Past and Present, 37, pp. 44-70.

- (1986): «Urban Growth and Agricultural Change: England and the Continent in the Early Modern Period», en Robert I. Rotberg y Theodore K. RAAB (eds.), Population and Economy: Population and History from the Traditional to the Modern World, Cambridge, Cambridge University Press.

Wrigley, E. A., y Abrams, Philip (eds.) (1978): Towns in Societies. Essays in Economic History and Historical Sociology, Cambridge, Cambridge University Press.

Yun Casalilla, Bartolomé (1985): "Aristocracia, señorío y crecimiento económico en Castilla: algunas reflexiones a partir de los Pimentel y los Enríquez (siglos xvI y xvII)», Revista de Historia Económica, III, pp. 443-472. 